\title{
A case series of children with adenovirus pneumonia: three-year experiences in a tertiary PICU
}

Jingyi Shi ${ }^{\dagger}$, Yiping Zhou ${ }^{\dagger}$, Fei Wang, Chunxia Wang, Huijie Miao, Ting Sun, Yijun Shan, Yun Cui ${ }^{*}$ and Yucai Zhang ${ }^{*}$ (D)

\begin{abstract}
Background: Describe the outcome of adenovirus pneumonia in a pediatric intensive care unit (PICU) over a 3-year period, to identify the risk factors that may be associated with worse outcome.

Methods: A retrospective observational study was performed in the PICU of children's hospital in Shanghai from July 2016 to June 2019. Sixty-seven children over 29 days to 14 years old with adenovirus pneumonia who were admitted to PICU with acute hypoxemic respiratory failure were included in this study. The primary outcome was hospital mortality, and secondary outcomes were hospital and PICU length of stay (LOS), and risk factors of worse outcome.

Results: Of 67 children with severe adenovirus pneumonia, the hospital mortality was $16.42 \%$ (11/67) and 28-day mortality was 14.93\% (10/67). Median Pediatric Risk of Mortality III (PRISM III) score at admission was 13 (interquartile range [IQR], 10-15). Median PICU LOS stay was 11 days (8-18d) and hospital LOS was 22 days (16-31d). Among children with extracorporeal membrane oxygenation $(n=9), 6$ cases survived and 3 cases died. The patients who need renal replacement therapy, neuromuscular blockade, parenteral nutrition, and packed red blood cell perfusion had higher hospital mortality $(p<0.001, p=0.041, p=<0.001, p=0.012$, respectively). Multivariate logistic analysis indicated that liver dysfunction and nosocomial infection were associated with high risk of mortality.
\end{abstract}

Conclusions: The hospital mortality of adenovirus pneumonia in our PICU was 16.42\%. Patients complicated liver dysfunction and co-infection \& nosocomial infection were associated with poor outcome.

Keywords: Adenovirus pneumonia, Outcome, Mortality, Pediatric intensive care unit (PICU)

\section{Background}

Adenovirus is a common pathogen of respiratory tract infection in all age groups. The clinical course of this virus infection in immunocompetent patients is usually self-limited. However, adenovirus infection can cause significant morbidity and mortality in young children or immunocompromised persons $[1,2]$. Moreover,

\footnotetext{
*Correspondence: cuiyun0815@163.com; zyucai2018@163.com

${ }^{\dagger}$ Jingyi Shi and Yiping Zhou contributed equally to this work.

Department of Critical Care Medicine, Shanghai Children's Hospital; Institute of Pediatric Critical Care, Shanghai Jiao Tong University, No.355 Luding Road, Putuo District, Shanghai 200062, China
}

adenovirus has been increasingly found to be involved in sporadic cases and outbreaks of community acquired pneumonia (CAP) in infants and young children [3-5]. In some patients adenovirus infection cause severe pneumonia, myocarditis, hepatitis, encephalitis, and disseminated disease [2], which may quickly lead to refractory respiratory failure, acute respiratory distress syndrome (ARDS), and multiple organ dysfunction syndrome (MODS). If patients did not receive timely treatment, the mortality rate is over $50 \%$ had been described $[3,6]$. Unfortunately, no effective antivirals or vaccines available for the prevention or treatment of adenovirus in

(c) The Author(s). 2020 Open Access This article is licensed under a Creative Commons Attribution 4.0 International License, which permits use, sharing, adaptation, distribution and reproduction in any medium or format, as long as you give appropriate credit to the original author(s) and the source, provide a link to the Creative Commons licence, and indicate if changes were made. The images or other third party material in this article are included in the article's Creative Commons licence, unless indicated otherwise in a credit line to the material. If material is not included in the article's Creative Commons licence and your intended use is not permitted by statutory regulation or exceeds the permitted use, you will need to obtain permission directly from the copyright holder. To view a copy of this licence, visit http://creativecommons.org/licenses/by/4.0/. The Creative Commons Public Domain Dedication waiver (http://creativecommons.org/publicdomain/zero/1.0/) applies to the data made available in this article, unless otherwise stated in a credit line to the data. 
children and adults either. Although Cidofovir reported to reduce the adenovirus load and to improve some series survivals, has not widely used in children yet. So, severe adenovirus pneumonia continued to provide pediatric intensive care unit (PICU) challenges.

The management of refractory hypoxic respiratory failure / ARDS seems to be improving in severe infection $[7,8]$. Recently, limited studies reported that blood hemofiltration and ECMO were potential effective support for severe adenovirus pneumonia. However, the outcome is still far from satisfactory [9-12]. Furthermore, there is little information available for identifying risk factors for morbidity and mortality with severe adenovirus pneumonia in PICU [13].

Based on Lee and colleague's study, adenovirus accounts for 5 to $10 \%$ of pediatric respiratory tract infection [14]. More recently, the incidence of pediatric adenoviral pneumonia has increased in some parts of China mainland [15]. The National Health Commission of China has issued the diagnosis and treatment of adenoviral pneumonia in children (2019) (http://www.nhc.gov.cn/yzygj/s7653p/2 01906/ab8ec27548ea48f793734e8d09c8d42c.shtml) recommended that children with severe illness should apply broad-spectrum antibiotics, glucocorticoids, bronchoscopy and mechanical ventilation. The indications of extracorporeal membrane lung (ECMO) and blood purification need to be carefully evaluated. Therefore, this retrospective observational study was conducted to better describe the clusters therapy strategies and outcomes of adenovirus infection in PICU.

\section{Methods}

\section{Study design and inclusion criteria}

We performed a retrospective analysis of prospectively collected data of patients with severe adenovirus pneumonia admitted to a 36-bed PICU in a tertiary university hospital (Shanghai Children's Hospital, Shanghai Jiao Tong University, China) between July 2016 and June 2019. All patients with pneumonia were initially screened with rapid respiratory virus assay including respiratory syncytial virus, adenovirus, influenza virus and coxsackie virus with nasopharyngeal swab at PICU admission. If rapid assay screen was negative, the deeper respiratory secretions obtained via endotracheal tube or bronchoalveolar lavage collected by bronchoscopy were tested by real-time polymerase chain reaction (RT-PCR). The inclusion criteria were an age of 29 days to 14 years old. Adenovirus pneumonia was confirmed by a positive RT-PCR from respiratory secretions as well as chest Xray. The exclusion included:1) Patient was hospital acquired adenovirus pneumonia;2) Children had been admitted to other hospital within the last 3 days prior to the present admission; and 3) Children re-admitted to the PICU without 7 days symptom-free period. The study was approved by the ethics committee of Hospital
(Approval number: 2016R007-E01). Informed consent was waived because of its retrospective design.

\section{Observational variables}

The clinical course of each patient was obtained through computerized medical record database at hospital. Patient outcomes were grouped into two categories: survivors and non-survivors. The primary end point was hospital mortality. Key secondary outcomes included 28day mortality, length of PICU stay and hospital stay, duration of mechanical ventilation and ventilator parameters, the clusters of therapy strategies: extracorporeal membrane oxygenation [ECMO] applied for refractory shock or refractory hypoxic respiratory failure, continuous renal replacement therapy or renal replacement therapy [CRRT/RRT] applied for fluid overload or acute kidney injury, prone position ventilation applied when the ratio of $\mathrm{PaO}_{2} / \mathrm{FiO}_{2}$ lower than $150 \mathrm{mmHg}$, and neuromuscular blockade applied when the ratio of $\mathrm{PaO}_{2} / \mathrm{FiO}_{2}$ lower than $150 \mathrm{mmHg}$ as well as the peak inspiration pressure higher than $27 \mathrm{cmH}_{2} \mathrm{O}$. And also, the vasoactive and steroids use, IV immunoglobulin, packed red blood cell perfusion, parenteral nutrition and etc. were recorded respectively.

The parameters including age, gender, pediatric risk of mortality III (PRISM III), the ratio of $\mathrm{PaO}_{2} / \mathrm{FiO}_{2}$, lung dynamic compliance (Cdyn), cardiac index (CI), mean arterial pressure (MAP), co-morbidities, secondary infection pathogen were collected. We also collect blood gas values and transcutaneous saturations. The biochemical parameters for organ functions (total bilirubin [TBIL]; lactic acid [LA]; serum creatinine [sCr]; etc.), Above laboratory indexes were collected from the first test within $24 \mathrm{~h}$ PICU admission. The laboratory indexes include white blood cell, platelet counts (PLT), natural kill cell (NK), cytokines and $\mathrm{T}$ lymphocytes series at within $24 \mathrm{~h}$ and after 7 days PICU admission.

\section{Statistical analysis}

Patient's characteristics and outcomes were summarized as median (interquartile range, IQR) for variables and percentage for categorical variables. Mann-Whitney $U$ test was used to compare the continuous variables with abnormally distributed data The Fisher's exact test or chi-square test was used to compare the categorical data. Adjusted odd ratios (ORs) were estimated by multivariate logistic regression models including the variables with significant difference obtained from group comparison. A value of $P<0.05$ was considered statistically significant. Data analyses were performed using Statistical analyses were performed using STATA 15.0 MP (College Station, Texas, USA). 


\section{Results}

Baseline characteristics

Of 842 patients with pneumonia that requires PICU admission during the study period, 671 cases were community-acquired pneumonia (CAP). Among CAP, 67 with primary adenovirus infection were identified, and adenovirus accounted for $9.99 \%$ for all severe CAP admission. The patient enrolment and study profile were shown in Fig. 1. Among included patients, the median age was 18 (10, 38.5) months and 40 patients (59.7\%) were male. Children aged $<24$ months accounted for $83.6 \%(56 / 67)$ of all cases. The main characteristics at initial PICU admission between survivors and nonsurvivors were summarized in Table 1.

All patients were admitted to PICU for the reasons of fever (100\%) and respiratory symptoms consistent with cough $(100 \%)$ or whoop (65.7\%), tachypnea (100\%), acute respiratory failure (100\%) requiring oxygenation support.

At PICU admission, co-infection (defined as pneumonia caused by adeno virus as well as typical bacteria, mycoplasma pneumoniae and other viruses) was seen in 25.37\% (17/67) patients. During the PICU stay, nosocomial infection including VAP and bloodstream infection were seen in $32.84 \%(22 / 67)$ patients, higher morbidity in non-survival $(63.6 \%, 7 / 11)$ than in survival $(26.78 \%, 15 /$ 56). Nosocomial infected pathogens were isolated from different specimens including blood, sputum, bronchoalveolar lavage fluid, and hydrothorax. The most frequently isolated pathogens were Acinetobacter baumanii
9 patients (13.4\%), Klebsiella pneumoniae in 7(10.5\%), mycoplasma pneumoniae in 6 (9.8\%), Stenotrophomonas maltophilia in 4 (5.9\%), and Candida albicans in 3 (4.5\%) (Table 2).

\section{Management and outcomes}

All management decisions were performed by intensivist according to the guideline recommendation $[8,16,17]$, experts' opinion [18], and routine practice in our PICU. Additional oxygen was utilized in $100 \%$ (67cases) patients with $8.96 \%$ (6cases) requiring high flow nasal oxygen therapy, and $92.54 \%$ (62cases) requiring mechanical ventilation at some period during hospitalization. The indications for CRRT/RRT were:1) AKI which was defined according to the KDIGO criteria [19]; 2) Fluid overload which was defined as the fluid overload $>10 \%$ [fluid overload $=($ CRRT initial weight-PICU admission weight)/PICU admission weight $\times 100 \%]$ [20, 21]. The indications for ECMO were:1) severe hypoxemia with a $\mathrm{PaO} 2 / \mathrm{FiO} 2$ ratio of $<50 \mathrm{mmHg}$ for $>3 \mathrm{~h}$ or $<80 \mathrm{mmHg}$ for $>6 \mathrm{~h}$, or $\mathrm{pH}<7.25$ and a partial pressure of arterial $\mathrm{CO} 2$ of $\geq 60 \mathrm{mmHg}$ for $>6 \mathrm{~h}$ [22]. 2) hypoxemia complicated with cardio dysfunction when cardiac index (CI) less than $2.2 \mathrm{~L} / \mathrm{min} . \mathrm{m} 2$; and 3) hypoxemia complicated with circulatory dysfunction when persistent lactatemia greater than $4 \mathrm{mmol} / \mathrm{L}$ and vasoactive inotropic score (VIS) greater than 50.VIS was calculated as ([(epinephrine+ norepinephrine $) \mathrm{ug} / \mathrm{kg} \cdot \mathrm{min}] \times 100+[($ dobutamine + dopamine) ug/kg.min $]+$ [milrinone ug/kg.min] $\times 15$. Intravenous

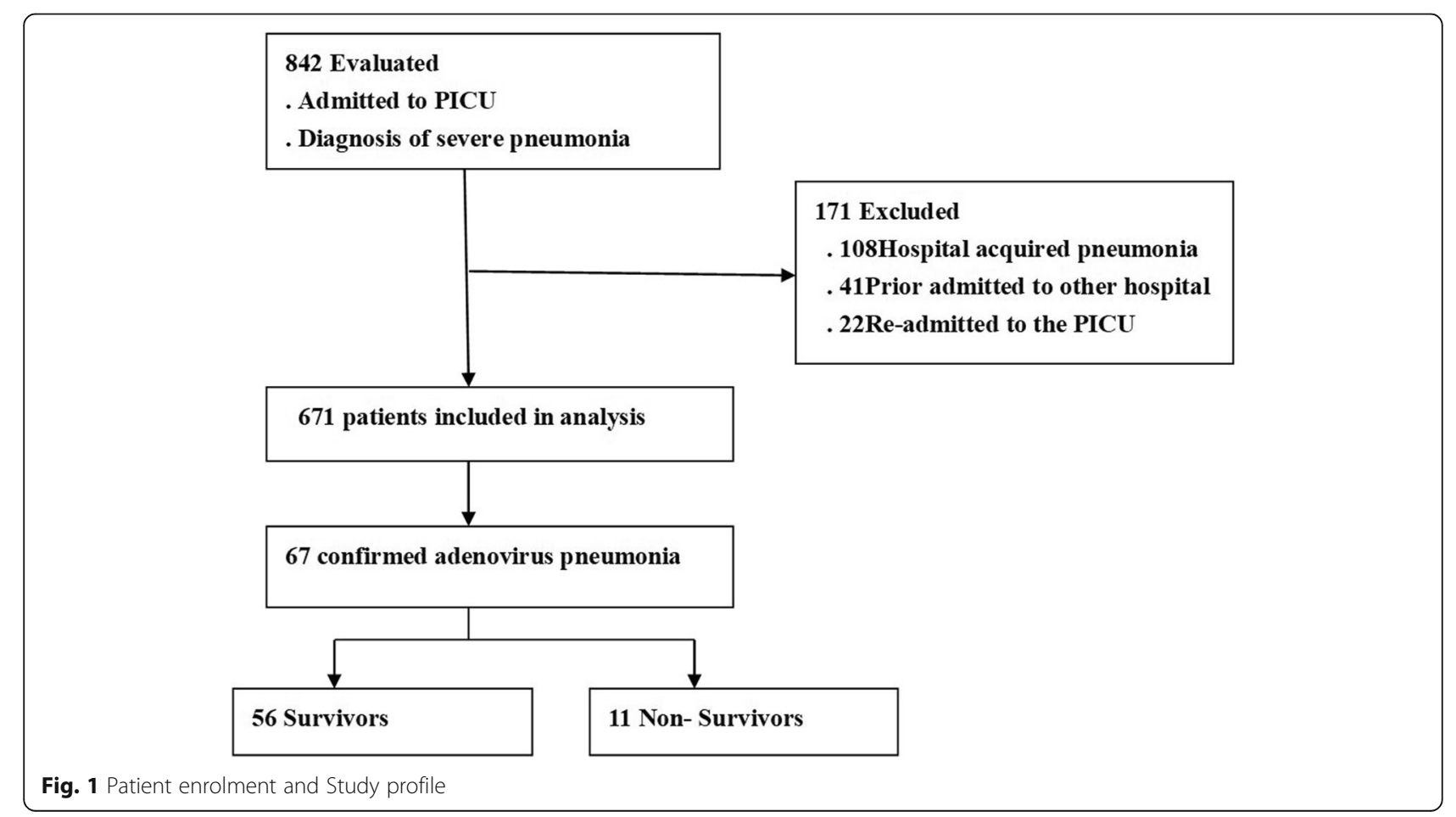


Table 1 Baseline characteristics at PICU admission between survivors and non-survivors

\begin{tabular}{|c|c|c|c|c|}
\hline Variables at PICU admission & Survivors $(\boldsymbol{n}=56)$ & Nonsurvivors $(\boldsymbol{n}=11)$ & Total $(\boldsymbol{n}=67)$ & $\boldsymbol{p}$ value \\
\hline Age, mo, median (IQR) & $18(11,38)$ & $20(7.5,41.5)$ & $18(10,38.5)$ & 0.889 \\
\hline Male gender, n (\%) & $32(57.14 \%)$ & $8(72.7 \%)$ & $40(59.7 \%)$ & 0.335 \\
\hline PRSM III score, median (IQR) & $13(10,15)$ & $14(11,18)$ & $13(10,15)$ & 0.133 \\
\hline days of illness before at PICU admission, median (IQR) & $9(7,10.5)$ & $6(5,12)$ & $9(6,11)$ & 0.959 \\
\hline \multicolumn{5}{|l|}{ Laboratory values, median (IQR) } \\
\hline White blood cell, 109/L & $6.55(4.36,12.23)$ & $6.11(4.35,10.87)$ & $6.48(4.29,11.96)$ & 0.923 \\
\hline Platelet, 109/L & $254(179,349.5)$ & $258(148.5,444.5)$ & $258(178,353)$ & 0.837 \\
\hline NK cells, \% & $3.85(2.23,6.57)$ & $5(2,6.9)$ & $4.06(2.19,6.68)$ & 0.787 \\
\hline $\mathrm{pH}$ & $7.4(7.33,7.44)$ & $7.33(7.28,7.42)$ & $7.4(7.33,7.44)$ & 0.109 \\
\hline $\mathrm{PaO} 2, \mathrm{mmHg}$ & $71(57,82.5)$ & $73(65.38,84.38)$ & $72(57,84)$ & 0.853 \\
\hline $\mathrm{PaCO} 2, \mathrm{~mm} \mathrm{Hg}$ & $43(38,55)$ & $52(44.5,68)$ & $44(38,55.5)$ & 0.104 \\
\hline MAP, mmHg & $55(52,68.25)$ & $49(42.5,57)$ & $55(51.5,67)$ & 0.171 \\
\hline $\mathrm{LA}, \mathrm{mmol} / \mathrm{L}$ & $1.95(1.38,2.33)$ & $2(1.65,4.25)$ & $2(1.4,2.6)$ & 0.968 \\
\hline $\mathrm{Cl}, \mathrm{L} / \mathrm{min} / \mathrm{m}^{2}$ & $4.2(3.9,5)$ & $3.6(3.45,4.1)$ & $4.2(3.85,4.85)$ & 0.011 \\
\hline TBIL,umol/L & $4.42(3.2,5.87)$ & $10.85(5.35,20.22)$ & $5.02(3.29,6.61)$ & 0.069 \\
\hline serum creatinine, umol/L & $32.5(25.5,40.88)$ & $34.5(29.25,54)$ & $33(26.25,42)$ & 0.291 \\
\hline
\end{tabular}

IQR interquartile range, NK cells natural kill cell; Cl: cardiac index, MAP mean arterial pressure, TBIL total bilirubin, LA Lactate

Table 2 PICU therapeutic interventions between survivors and non-survivors

\begin{tabular}{|c|c|c|c|c|}
\hline & Survivors $(\boldsymbol{n}=56)$ & Non-survivors $(\boldsymbol{n}=11)$ & Total $(\boldsymbol{n}=67)$ & $\boldsymbol{p}$ value \\
\hline Median of PICU stay, days & $11(7.75,18)$ & $15(11,19.5)$ & $11(8,18)$ & 0.861 \\
\hline Median of hospital stay, days & $22.5(16,34.25)$ & $17(16,23.5)$ & $22(16,31)$ & 0.124 \\
\hline \multicolumn{5}{|l|}{ Co-morbidity, n (\%) } \\
\hline ARDS & $27(48.21 \%)$ & $9(81.82 \%)$ & $36(53.73 \%)$ & 0.041 \\
\hline Liver dysfunction & $21(31.34 \%)$ & $10(90.9 \%)$ & $31(46.27 \%)$ & 0.001 \\
\hline AKI & $4(7.14 \%)$ & $5(45.45 \%)$ & $9(13.43 \%)$ & 0.001 \\
\hline shock & $42(75 \%)$ & $10(90.9 \%)$ & $52(77.61 \%)$ & 0.247 \\
\hline Gl dysfunction & $31(55.36 \%)$ & $11(100 \%)$ & $42(62.69 \%)$ & 0.005 \\
\hline \multicolumn{5}{|l|}{ PICU and hospital therapies, n (\%) } \\
\hline Invasive Mechanical ventilation & $51(91.07 \%)$ & $11(100 \%)$ & $62(92.54 \%)$ & 0.303 \\
\hline CRRT/RRT & $11(19.64 \%)$ & $8(72.73 \%)$ & $19(28.36 \%)$ & $<0.001$ \\
\hline ECMO & $6(10.71 \%)$ & $3(37.5 \%)$ & $9(13.43 \%)$ & 0.141 \\
\hline Prone positioning, n (\%) & $15(26.79 \%)$ & $4(36.36 \%)$ & $19(28.36 \%)$ & 0.519 \\
\hline Neuromuscular blockade, n (\%) & $22(39.29 \%)$ & $8(72.73 \%)$ & $30(44.78 \%)$ & 0.041 \\
\hline Vasoactive use & $48(85.71 \%)$ & $10(90.9 \%)$ & $58(86.57 \%)$ & 0.644 \\
\hline diuretics use & $43(76.79 \%)$ & $8(72.73 \%)$ & $51(76.12 \%)$ & 0.773 \\
\hline Steroids use & $55(98.21 \%)$ & $11(100 \%)$ & $66(98.51 \%)$ & 0.655 \\
\hline IV immunoglobulin & $50(89.29 \%)$ & $10(90.9 \%)$ & $60(89.55 \%)$ & 0.872 \\
\hline Parenteral nutrition & $12(21.43 \%)$ & $10(90.9 \%)$ & $22(32.84 \%)$ & $<0.001$ \\
\hline Packed red blood cell perfusion & $28(50 \%)$ & $10(90.9 \%)$ & $38(56.72 \%)$ & 0.012 \\
\hline Nosocomial infenction ${ }^{\mathrm{a}}, \mathrm{n}(\%)$ & $15(26.79 \%)$ & 7 (63.64\%) & $22(32.84 \%)$ & 0.017 \\
\hline bacterial & $15(26.79 \%)$ & $7(63.64 \%)$ & $22(32.84 \%)$ & 0.043 \\
\hline fungal & $4(7.14 \%)$ & $1(9.09 \%)$ & $5(7.46 \%)$ & 0.687 \\
\hline
\end{tabular}

aparts of patients complicated with bacteria, mycoplasma pneumoniae or fungi in nosocomial infection or co-infection 
neuromuscular blockade was started if the peak inspiratory pressures approximated $28-30 \mathrm{cmH} 2 \mathrm{O}$, and the patient was hypoxemic and continued to show excessive work of breathing despite adequate sedation [23]. Other cluster therapies included prone positioning, IV immunoglobulin, parenteral nutrition, vasoactive drugs, packed red blood cell perfusion, steroids (methylprednisolone $0.5-2.0 \mathrm{mg} / \mathrm{kg} . \mathrm{d}$ for $3-5$ days), diuretics, and antibiotics if needed (see in Table 2).

Among the 67 patients with severe adenovirus pneumonia, 11(16.42\%) children died in PICU and among them, 10 (14.93\%) cases died within 28 day after PICU admission. The overall PICU mortality was $16.42 \%$ (11/ 67), and 28-day mortality was $14.93 \%$ (10/67). Patients aged less 2-year old accounted for $72.73 \%$ (8/11) of nonsurvivors.

The median lengths of stay in the PICU and hospital were 11 days $(8,18$ days) and 22 days $(16,31$ days), respectively (Table 2). The median duration of mechanical ventilation was 5.75 days $(3.98,11.67)$ in patients required invasive ventilation. In non-survivors, the median ventilator days was longer than that in survivors but without statistical significance $(8.48[4.77,11.82]$ days vs. $10.75[8.17,19.08]$ days, $p=0.348)$. The rate of CRRT and use of neuromuscular blockade, parenteral nutrition, or packed red blood cell perfusion were significantly higher in non-survivors than that in survivors $(p<0.001$, $p=0.041, p<0.001, p=0.012$, respectively; Table 2). Moreover, the ratio of nosocomial infection was higher in non-survivors compared with survivors $(63.64 \%$ vs. $26.79 \%, p=0.017$; Table 2).

The changes of parameters about ventilator characteristics and blood gas analysis in survivors and non- survivors were shown in Table 3 . There were no significant differences in parameters including peak inspiratory pressure (PIP), positive expiratory end pressure (PEEP) and mean airway pressure (MAP) on the initial day, 3rd day and 7th day of invasive ventilation between survivors and non -survivors (all $p>0.05$, Table 3 ). However, the values of Cydn on 3rd day and 7th day of invasive ventilation were significantly lower in non-survivors compared with survivors $(p=0.012, p=0.045$, Table 3$)$. In addition, the ratio of $\mathrm{PaO}_{2} / \mathrm{FiO}_{2}$ and $\mathrm{SaO}_{2}$ levels displayed a tendency decrease in non-survivors compared with survivors on the 3rd day after receiving invasive mechanical ventilation $(p=0.038, p=0.008$, respectively; Table 3).

Besides the lower cardiac index (CI) in non-survivors than survivors at PICU admission (Table 1), $\mathrm{CD} 4^{+}$cells percentage showed a higher tendency in non-survivors than that in survivors at PICU admission $(p=0.071$, Table 4). There were no significant differences in aspects of white blood cell and platelet count, NK cell, CD4 ${ }^{+}$, $\mathrm{CD}^{+}, \mathrm{CD}_{19^{+}}$percentage between two groups at PICU admission. During PICU stay, platelet Count was significantly lower in non-survivors at 7 days after PICU admission when compared with survivors $(93$ [85, 371], vs. $327[257.75,443.75] \times 10^{9} / \mathrm{L}, p=0.039 ;$ Table 4$)$. In addition, the interleukin 6 (IL-6) and IL-10 were significantly higher in non-survivors than those of survivors at 7 days after PICU admission $(p=0.035, p<0.01$, respectively; Table 4).

\section{Multivariate logistic analysis}

By univariate logistic analysis, the patients were associated with worse outcome of severe adenovirus

Table 3 The changes of parameters about patients receiving invasive mechanical ventilation

\begin{tabular}{|c|c|c|c|c|c|c|c|c|c|}
\hline \multirow[t]{2}{*}{ Variables } & \multicolumn{3}{|l|}{ D1 } & \multicolumn{3}{|l|}{ D3 } & \multicolumn{3}{|l|}{ D7 } \\
\hline & $\begin{array}{l}\text { Survivor } \\
(n=56)\end{array}$ & $\begin{array}{l}\text { Nonsurvivor } \\
(n=11)\end{array}$ & $p$-value & $\begin{array}{l}\text { Survivors } \\
(n=56)\end{array}$ & $\begin{array}{l}\text { Nonsurvivor } \\
(n=11)\end{array}$ & $\begin{array}{l}P \text { - } \\
\text { value }\end{array}$ & $\begin{array}{l}\text { Survivor } \\
(n=56)\end{array}$ & $\begin{array}{l}\text { Nonsurvivor } \\
(n=11)\end{array}$ & $p$-value \\
\hline $\mathrm{PIP}, \mathrm{cmH}_{2} \mathrm{O}$ & $21(19,23.5)$ & $25(21,27)$ & 0.145 & $21.5(20,24)$ & $24(20.5,28)$ & 0.377 & $22(20,26)$ & $23(21.75,30)$ & 0.27 \\
\hline $\mathrm{MAP}, \mathrm{cmH}_{2} \mathrm{O}$ & $11(10,12.5)$ & $12(10.5,13.5)$ & 0.372 & $11.5(9.25,13)$ & $12(11,14.5)$ & 0.412 & $12(11.5,14.5)$ & $13(11,17.25)$ & 0.458 \\
\hline PEEP, $\mathrm{cm} \mathrm{H}_{2} \mathrm{O}$ & $5(4,5)$ & $5(4,5)$ & 0.368 & $5(5,6)$ & $5(5,5.5)$ & 0.801 & $5(5,6)$ & $6(5,6)$ & 0.567 \\
\hline Cdyn, $\mathrm{cm} \mathrm{H} \mathrm{H}_{2} \mathrm{O} / \mathrm{kg}$ & $0.4(0.32,0.48)$ & $\begin{array}{l}0.33(0.31 \\
0.425)\end{array}$ & 0.286 & $\begin{array}{l}0.52(0.43, \\
0.55)\end{array}$ & $0.4(0.31,0.4)$ & 0.012 & $0.5(0.4,0.56)$ & $0.26(0.22,0.34)$ & 0.045 \\
\hline $\begin{array}{l}\text { Tidal volume, } \\
\mathrm{ml} / \mathrm{kg}\end{array}$ & $8(7.8,8)$ & $7.2(6.65,8)$ & 0.0029 & $8.3(8,8.5$ & $8(7.2,8.1)$ & 0.072 & $8.2(8,8.5)$ & $7.55(6.03,8.35)$ & 0.307 \\
\hline $\begin{array}{l}\mathrm{PaO}_{2} / \mathrm{FiO}_{2} \text { ratio, } \\
\mathrm{mmHg}\end{array}$ & $151(113,180.25)$ & $140(90,143.5)$ & 0.177 & $185(139,224)$ & $111(103,174.5)$ & 0.038 & $170(110,212)$ & $137.5(89.5,157.75)$ & 0.384 \\
\hline \multicolumn{10}{|l|}{ Oxygenation index } \\
\hline $\mathrm{PaCO}_{2}, \mathrm{~mm} \mathrm{Hg}$ & $44(35,50.25)$ & $48(41.5,57.5)$ & 0.138 & $45(40.5,48.5)$ & $42(37.5,55.5)$ & 0.727 & $44(41,48)$ & $58(43,69.5)$ & 0.305 \\
\hline $\mathrm{PaO}_{2}, \mathrm{~mm} \mathrm{Hg}$ & $72(57,86.25)$ & $73(58.375,84.5)$ & 0.871 & $78(72.5,89.5)$ & $78(72.5,89.5)$ & 0.087 & $77(55,90)$ & $65(51.5,75)$ & 0.357 \\
\hline $\mathrm{SaO}_{2}, \%$ & $95(92,96)$ & $93(90.5,95)$ & 0.265 & $96(95,97)$ & $93(91.5,95.5)$ & 0.008 & $96.5(92.25,98)$ & $91(89,95.5)$ & 0.655 \\
\hline
\end{tabular}

D1: initial day of invasive mechanical ventilation; D3: 3 days of ventilation; D7: 7 days of ventilation; PIP: Cdyn: lung dynamic compliance; MAP mean airway pressure 
Table 4 Changes of blood cell and immunological parameters at PICU admission and 7 days after admission

\begin{tabular}{|c|c|c|c|c|c|c|}
\hline \multirow[t]{2}{*}{ Variables } & \multicolumn{3}{|l|}{ PICU admission } & \multicolumn{3}{|l|}{7 days after admission } \\
\hline & Survivors $(\boldsymbol{n}=56)$ & Non-survivors $(\boldsymbol{n}=11)$ & $\boldsymbol{P}$ value & Survivors $(\boldsymbol{n}=56)$ & Non-survivors $(\boldsymbol{n}=11)$ & $\boldsymbol{P}$ value \\
\hline $\mathrm{Hb}, \mathrm{g} / \mathrm{L}$ & $101.5(90,113.5)$ & $100(100,109.5)$ & 0.699 & $99.5(95,106)$ & $95(90,110)$ & 0.457 \\
\hline WBC, $10^{9} / \mathrm{L}$ & $6.55(4.36,12.23)$ & $6.11(4.35,10.87)$ & 0.923 & $8.78(5.26,10.77)$ & $4.37(3.39,11.69)$ & 0.774 \\
\hline platlat, $10^{9} / \mathrm{L}$ & $254(179,349.5)$ & $258(148.5,444.5)$ & 0.837 & $327(257.75,443.75)$ & $93(85,371)$ & 0.039 \\
\hline NK cells, \% & $3.85(2.23,6.57)$ & $5(2,6.895)$ & 0.787 & $3.98(2.185,6.01)$ & $2.98(1.02,8.08)$ & 0.812 \\
\hline CD19+, \% & $44.02(30.91,52.64)$ & $42.1(24.47,53.55)$ & 0.437 & $34.58(30.13,45.36)$ & $38.58(24.66,44.04)$ & 0.804 \\
\hline $\mathrm{CD} 4+, \%$ & $25.56(19.5,31.39)$ & $32.48(23.2,41.59)$ & 0.071 & $27.49(22.96,35.48)$ & $33.23(29.82,38.79)$ & 0.489 \\
\hline CD8+, \% & $20.02(14.96,26.75)$ & 16.36 (15.34 20.25) & 0.555 & $20.14(17.76,28.28)$ & $20.58(14.23,22.5)$ & 0.614 \\
\hline IL-6, ng/L & $0.1(0.1,0.1)$ & $0.1(0.1,0.1)$ & 0.449 & $0.1(0.1,0.1)$ & $47.77(0.1,239.29)$ & 0.035 \\
\hline IL-8, ng/L & $0.1(0.1,12.09)$ & $0.1(0.1,36.39)$ & 0.707 & $0.1(0.1,0.1)$ & $7.15(3.09,20.21)$ & 0.144 \\
\hline IL-10, ng/L & $0.1(0.1,4.05)$ & $8.99(0.1,32.57)$ & 0.855 & $0.1(0.1,0.1)$ & $18.39(0.1,32.74)$ & 0.0005 \\
\hline IL-2R, ug/L & $15.31(4.27,28.78)$ & $18.92(11.38,33.37)$ & 0.459 & $10.25(20.81,24.32)$ & 21.71 (16.37 33.43) & 0.089 \\
\hline
\end{tabular}

pneumonia in complicated liver dysfunction due to the adeno virus infection (16.485 [1.745 155.705], $p=$ $0.014)$, AKI (10.833[2.269 51.706], $p=0.003)$, gastrointestinal dysfunction (0.355 [0.178 0.706], $p=0.003)$ which was defined according to the European Consensus Definition of acute gastrointestinal injury (AGI) [24], encephalopathy $(5.629 \quad[1.333 \sim 23.774], \quad p=0.019)$, coinfection \& nosocomial infection (15.455 [1.847 $129.326], p=0.012$ ) (Table 5). By multivariate logistic regression analysis, the independently risk factor associated with mortality was liver dysfunction (21.231 [1.696 $\sim 265.779$ ], $p=0.018)$ and nosocomial infection (2.574 [0.986 15.671], $p=0.05$ ) (Table 5).

\section{Discussion}

This is the first REPORT describing overall morbidity and mortality for pediatric patients with severe adenoviral pneumonia admitted to the PICU in mainland China. In our PICU 3-year period, the hospital all-cause hospital mortality of severe community acquired adenoviral pneumonia was $16.42 \%$, and 28 -day mortality (deaths after discharge from hospital were not included) was $14.93 \%$. In the 11 non-survivor patients, 3 of them died from liver dysfunction due to adeno virus infection, 3 died from refractory hypoxic respiratory failure, two of them died from refractory septic shock caused by nosocomial infection of Klebsiella pneumoniae and Stenotrophomonas maltophili, and one patient died from intracranial bleeding. We identified the independently risk factors for mortality including patients complicated with liver dysfunction and nosocomial infection.

Adenovirus disease is a self-limiting in majority of immunocompetent population, but can cause lifethreatening illness in immunocompromised hosts [2527]. Adenovirus accounts for at least 5 to $10 \%$ of pediatric respiratory tract infections in children $[1,2]$. The overall PICU hospitalization with severe adenoviral pneumonia in the present study was $9.99 \%$ of CAP. More importantly, the cases number from 2016 to 2019 was with increased tendency in our PICU, especially with

Table 5 Logistic analysis of variables independently associated with hospital mortality

\begin{tabular}{|c|c|c|c|c|}
\hline Outcome & OR & St.Err. & $95 \% \mathrm{Cl}$ & $P$ value \\
\hline \multicolumn{5}{|l|}{ Univariate logistic regression } \\
\hline PRISM III & 1.079 & 0.119 & $0.868 \sim 1.342$ & 0.690 \\
\hline ARDS & 0.5 & 0.185 & $0.242 \sim 1.032$ & 0.061 \\
\hline Liver dysfunction & 16.485 & 18.887 & $1.745 \sim 155.705$ & 0.014 \\
\hline AKI & 10.833 & 8.639 & $2.269 \sim 51.706$ & 0.003 \\
\hline Shock & 3.333 & 3.644 & $0.391 \sim 28.41$ & 0.271 \\
\hline Gastrointestinal dysfunction & 0.355 & 0.124 & $0.178 \sim 0.706$ & 0.003 \\
\hline Encephalopathy & 5.629 & 4.138 & $1.333 \sim 23.774$ & 0.019 \\
\hline Co-infection\& nosocomial infection & 15.455 & 16.751 & $1.847 \sim 129.326$ & 0.012 \\
\hline \multicolumn{5}{|l|}{ Multivariate logistic regression } \\
\hline Liver dysfunction & 21.231 & 27.376 & $1.696 \sim 265.779$ & 0.018 \\
\hline nosocomial infection & 2.574 & 0.706 & $0.986 \sim 15.671$ & 0.05 \\
\hline
\end{tabular}


a higher incidence rate between 2018 to 2019. Most patients with adenovirus infection are younger than 2-year old [56/ 67,83.6\%]. When severe adenovirus pneumonia progressed with MODS, the mortality is higher over 50\% [5]. In the present study, children aged $<24$ months accounted for $72.73 \%$ of total deaths. There are limited antiviral drugs available for adenovirus. Cidofovir is an antiviral drug which use has been associated with significant reductions of adenovirus load and, in some series improved survival in reports [10, 28]. Until recently, Cidofovir is not available in China till 2019, and has been neither widely used in children, nor has it been used in our cases. All these results suggested that adenovirus pneumonia requires our attention due to the high mortality involved, especially in China where there have no specific anti-adenovirus drugs or vaccine for children until now.

Mechanical ventilation remains the main stay of management. For the hypoxemia respiratory failure/ARDS ventilated patients caused by adenovirus in this study, the $\mathrm{PaO}_{2} / \mathrm{FiO}_{2}$ ratio at initial presentation was relatively low in survivors (151[interquartile range:113, 180.25]) and non-survivors (140[interquartile range:107, 143.5]). The $\mathrm{PaO}_{2} / \mathrm{FiO}_{2}$ was no statistical difference at initial day, 3rd day and 7th day ventilation between survivors and nonsurvivors. But lower Cdyn at 3rd day and 7th day ventilation in non-survivors $(p=0.012, p=0.045)$. In order to ensure the mechanical ventilation and to improve the level of $\mathrm{PaO}_{2} / \mathrm{FiO}_{2}$, we used prone position and neuromuscular blockers in appropriate patients. There was no difference in the proportion of prone position between the two groups $(p=0.519)$, but the proportion of neuromuscular blockers was significantly higher in non-survivors than that in survivors $(p=0.041)$.

Under 2-year old could partially contribute to the high incidence of severe adenovirus pneumonia and high mortality [2, 24-26]. Adenovirus-induced immunosuppression might augment the susceptibility to nosocomial microbial infections. In this retrospective study, the high levels of IL-6 and IL-10 in non-survivors were measured, and we identified that the nosocomial infection after PICU admission was an independent risk factors for allcause hospital mortality. This indicated that high levels of IL-6 and IL-10 in non-survivors could provide an insight for adenovirus-associated nosocomial infection. IL-6 plays a role in immunosuppression by driving differentiation of myeloid suppressor cells together with TGF- $\beta$ in cancer pathogenesis [29]. Otherwise, IL-10 is produced by Treg cells and Th2-type cells and suppresses the Th1 response [30]. The continued release of IL-10 contributes to sepsis-induced immunosuppression resulting in more susceptibility to nosocomial infection [31, 32]. Whether high levels of IL-6 and IL-10 in patients with adenovirus infection contribute the worse outcome warrants further investigation.
ECMO support for severe adenoviral infection has been reported in several studies [10, 33, 34]. Retrospective data from the extracorporeal life support organization (ELSO) registry showed that pediatric patients with AV infection supported with ECMO, had a survival to hospital discharge of $38 \%$ which was even lower in neonates [8]. B More recently, Ramanathan et al. observed over the last 25 years ELSO registry across all age groups who needed ECMO for severe adenoviral pneumonia in neonatal, pediatric, and adult patients, the hospital mortality was 58\% with no significant improvement from 1992 to 2016 [12]. In our study, 6 patients survived in whom (9cases) received ECMO support from 2016 to 2019. Our results suggest that ECMO as the last rescue treatment for severe adenoviral pneumonia, is worthy of further exploration.

Our study has several limitations. First, it is a retrospective analysis from single PICU, we didn't include those adeno virus pneumonia not requiring PICU admission, which contributed to the power of our study is limited by the small size of case series. Second, we didn't detect of adenovirus serotype, which might affect the judgment of the outcomes. Third, long-term follow-up data was unavailable.

\section{Conclusion}

Our study demonstrated that adenovirus pneumonia remains a major cause of morbidity and mortality in the PICU. We identified several factors with higher mortality, including complicated with shock, liver dysfunction, AKI, gastrointestine dysfunction, encephalopathy, and coinfection\& nosocomial infection. The patients complicated with liver dysfunction and associated nosocomial infection were independent risk factors for mortality.

\section{Abbreviations}

PICU: Pediatric intensive care unit; CAP: Community acquired pneumonia; ARDS: Acute respiratory distress syndrome; MODS: Multiple organ dysfunction syndrome; RT-PCR: Real-time polymerase chain reaction; ECMO: Extracorporeal membrane oxygenation; CRRT/RRT: Continuous renal replacement therapy/ renal replacement therapy; $\mathrm{PaO}_{2} / \mathrm{FiO}_{2}$ : The ratio of the partial pressure of oxygen in arterial blood ( $\mathrm{PaO} 2)$ to the inspired oxygen fraction (FiO2); PRISM III: Pediatric risk of mortality III; Cdyn: Lung dynamic compliance; Cl: Cardiac index; MAP: Mean arterial pressure; TBIL: Total bilirubin; LA: Lactic acid; sCr: serum creatinine; PLT: Platelet counts; NK: Natural kill cell; IQR: Interquartile range; ORs: Odd ratios; AKI: Acute kidney injury; ELSO: Extracorporeal life support organization

\section{Acknowledgements}

We acknowledge that our manuscript has been presented as a poster of the conference: AS16 Sepsis / Infections in the Critical Care Unit / Antimicrobial Stewardship / Tropical and Parasite Infections.

\section{Authors' contributions}

Conceived and designed the study: CXW and YCZ. Collected and analyzed data: JYS, YPZ, TS and YJS. Contributed analysis tools: FW and HJM. Contributed to discussion: JYS, YC and YCZ. Wrote the paper: JYS, YPZ, YC and YCZ. All authors read and approved the final manuscript.

\section{Funding}

This study was supported by the Multicenter Clinical Research Program of Shanghai Jiao Tong University School of Medicine (DLY201618), funded by 
the Science and Technology Commission of Shanghai Municipality (18411951000), grant supported by Shanghai Children's Hospital (2019XGLC01, 2018YLY004). The funders had no role in the study design, data collection or analysis, decision to publish, or preparation of the manuscript.

\section{Availability of data and materials}

Our present study was a retrospective observational study. All the data were obtained from medical records of patients. The datasets used and/or analysed during the current study are not publically available, but they can be shared from the corresponding author on reasonable request except for the identifying/confidential patient data.

\section{Ethics approval and consent to participate}

This study was approved by Ethics Review Committee, Children's Hospital of Shanghai/Shanghai Children's Hospital, Shanghai Jiao Tong University and conducted in accordance with the provisions of the Declaration of Helsinki (Approval number: 2016R007-E01). Informed content consent was waived because of its retrospective design.

\section{Consent for publication}

Not applicable.

\section{Competing interests}

The authors have declared that no competing interests exist.

Received: 7 April 2020 Accepted: 2 August 2020

Published online: 10 August 2020

\section{References}

1. Lynch JP, Fishbein M, Echavarria M. Adenovirus. Semin Respir Crit Care Med. 2011;32:494-511.

2. Lynch JP 3rd, Kajon AE. Adenovirus: epidemiology, global spread of novel serotypes, and advances in treatment and prevention. Semin Respir Crit Care Med. 2016:37(4):586-602.

3. Radke JR, Cook JL. Human adenovirus infections: update and consideration of mechanisms of viral persistence. Curr Opin Infect Dis. 2018;31:251-6.

4. Lee E, Kim CH, Lee YJ, Kim HB, Kim BS, Kim HY, et al. Annual and seasonal patterns in etiologies of pediatric community-acquired pneumonia due to respiratory viruses and mycoplasma pneumoniae requiring hospitalization in South Korea. BMC Infect Dis. 2020;20(1):132.

5. Chowdhury F, Shahid ASMSB, Ghosh PK, Rahman M, Hassan MZ, Akhtar Z, et al. Viral etiology of pneumonia among severely malnourished under-five children in an urban hospital, Bangladesh. PLoS One. 2020;15(2):e0228329.

6. Lion T. Adenovirus infections in immunocompetent and immunocompromised patients. Clin Microbiol Rev. 2014;27:441-62.

7. Bellani G, Laffey JG, Pham T, Fan E, Brochard L, Esteban A, et al. Epidemiology, patterns of care, and mortality for patients with acute respiratory distress syndrome in intensive care units in 50 countries. JAMA. 2016;315:788-800.

8. Khemani RG, Smith LS, Zimmerman JJ, Erickson S, Pediatric Acute Lung Injury Consensus Conference Group, et al. Pediatric acute respiratory distress syndrome: definition, incidence, and epidemiology: proceedings from the pediatric acute lung injury consensus conference. Pediatr Crit Care Med. 2015;16:S23-40.

9. Prodhan P, Bhutta AT, Gossett JM, Stroud MH, Rycus PT, Bratton SL, et al. Extracorporeal membrane oxygenation support among children with adenovirus infection: a review of the extracorporeal life support organization registry. ASAIO J. 2014;60:49-56.

10. Lee M, Kim S, Kwon OJ, Kim JH, Jeong I, Son JW, et al. Treatment of adenoviral acute respiratory distress syndrome using cidofovir with extracorporeal membrane oxygenation. J Intensive Care Med. 2017;32:231-8.

11. Gupta P, Tobias JD, Goyal S, Hervie P, Harris JB, Sadot E, et al. Prolonged mechanical support in children with severe adenoviral infections: a case series and review of the literature. J Intensive Care Med. 2011;26:267-72.

12. Ramanathan K, Tan CS, Rycus P, MacLaren G. Extracorporeal membrane oxygenation for severe adenoviral pneumonia in neonatal, pediatric, and adult patients. Pediatr Crit Care Med. 2019;20(11):1078-84.

13. Binder AM, Biggs HM, Haynes AK, Chommanard C, Lu X, Erdman DD, et al. Human adenovirus surveillance - United States, 2003-2016. MMWR Morb Mortal Wkly Rep. 2017;66(39):1039-42.
14. Lee J, Choi EH, Lee HJ. Comprehensive serotyping and epidemiology of human adenovirus isolated from the respiratory tract of Korean children over 17 consecutive years (1991-2007). J Med Virol. 2010;82:624-31.

15. Wu PQ, Zeng SQ, Yin GQ, Huang JJ, Xie ZW, Lu G, et al. Clinical manifestations and risk factors of adenovirus respiratory infection in hospitalized children in Guangzhou, China during the 2011-2014 period. Medicine (Baltimore). 2020;99:e18584

16. Dellinger RP, Levy MM, Rhodes A, Annane D, Gerlach H, Opal SM, et al. Surviving sepsis campaign guidelines for management of severe sepsis and septic shock. Intensive Care Med. 2013;34:783-5.

17. Davis AL, Carcillo JA, Aneja RK, Deymann AJ, Lin JC, Nguyen TC, et al. American College of Critical Care Medicine Clinical Practice Parameters for hemodynamic support of pediatric and neonatal septic shock. Crit Care Med. 2017:45:1061-93.

18. Chiumello D, Brochard L, Marini JJ, Slutsky AS, Mancebo J, Ranieri VM, Thompson BT, Papazian L, Schultz MJ, Amato M, et al. Respiratory support in patients with acute respiratory distress syndrome: an expert opinion. J Crit Care. 2017;21(1):240

19. Sutherland SM, Byrnes JJ, Kothari M, et al. AKI in hospitalized children: comparing the pRIFLE, AKIN, and KDIGO definitions. Clin J Am Soc Nephrol. 2015;10:554-61.

20. Miao H, Shi J, Wang $\mathrm{C}$, et al. Continuous renal replacement therapy in pediatric severe Sepsis: a propensity score-matched prospective multicenter cohort study in the PICU. Crit Care Med. 2019;47:e806-13.

21. Goldstein SL, Currier H, Graf C, et al. Outcome in children receiving continuous venovenous hemofiltration. Pediatrics. 2001;107:1309-12.

22. Patel B, Chatterjee S, Davignon S, Herlihy JP. Extracorporeal membrane oxygenation as rescue therapy for severe hypoxemic respiratory failure. J Thorac Dis. 2019;11(Suppl 14):S1688-97.

23. Wilsterman MEF, de Jager P, Blokpoel R, Frerichs I, Dijkstra SK, Albers MJ, et al. Short-term effects of neuromuscular blockade on global and regional lung mechanics, oxygenation and ventilation in pediatric acute hypoxemic respiratory failure. Ann Intensive Care. 2016;6(1):103-13.

24. Reintam Blaser A, Malbrain ML, Starkopf J, et al. Gastrointestinal function in intensive care patients: terminology, definitions and management. Recommendations of the ESICM working group on abdominal problems. Intensive Care Med. 2012;38(3):384-94.

25. Echavarria M. Adenoviruses in immunocompromised hosts. Clin Microbiol Rev. 2008;21:704-15.

26. Ghanaiem H, Averbuch D, Koplewitz BZ, Yatsiv I, Braun J, Dehtyar N, Wolf DG, Mandelboim M, Engelhard D. An outbreak of adenovirus type 7 in a residential facility for severely disabled children. Pediatr Infect Dis J. 2011;30:948-52.

27. Peled N, Nakar C, Huberman H, Scherf E, Samra Z, Finkelstein Y, Hoffer V, Garty BZ. Adenovirus infection in hospitalized immunocompetent children. Clin Pediatr (Phila). 2004;43:223-9.

28. Ganapathi L, Arnold A, Jones S, Patterson A, Graham D, Harper M, Levy O. Use of cidofovir in pediatric patients with adenovirus infection. F1000Res. 2016:5:758.

29. Eriksson E, Milenova I, Wenthe J, Moreno R, Alemany R, Loskog A. IL-6 signaling blockade during CD40-mediated immune activation FavorsAntitumor factors by reducing TGF- $\beta$, collagen type I, and PD-L1/PD1. J Immunol. 2019;202(3):787-98.

30. Muehlstedt SG, Lyte M, Rodriguez JL, Muehlstedt SG, Lyte M, Rodriguez JL. Increased il-10 production and hla-dr suppression in the lungs of injured patients precede the development of nosocomial pneumonia. Shock. 2002;17(6):443-50.

31. Oberholzer A, Oberholzer C, Moldawer LL. Interleukin-10: a complex role in the pathogenesis of sepsis syndromes and its potential as an antiinflammatory drug. Crit Care Med. 2002;30(Suppl):S58-63.

32. Ono S, Tsujimoto H, Hiraki S, Aosasa S. Mechanisms of sepsis-induced immunosuppression and immunological modification therapies for sepsis. Ann Gastroenterol Surg. 2018;2(5):351-8.

33. Allibhai TF, Spinella PC, Meyer MT, Hall BH, Kofos D, DiGeronimo RJ. Survival after prolonged pediatric extracorporeal membrane oxygenation support for adenoviral pneumonia. J Pediatr Surg. 2008;43(8):e9-11.

34. Ha SO, Kim HS, Park S, Jung KS, Jang SH, Han SJ, Kim HS, Lee SH. Severe ARDS caused by adenovirus: early initiation of ECMO plus continuous renal replacement therapy. SpringerPlus. 2016:5(1):1909.

\section{Publisher's Note}

Springer Nature remains neutral with regard to jurisdictional claims in published maps and institutional affiliations. 